\title{
Ampliando los significados de Sevicia: Los reclamos de protección corporal de los esclavos en Santiago de Cuba (1810-1870)
}

\author{
Expanding the Meanings of Sevicia: Enslaved People's Claims to \\ Bodily Protection in Santiago de Cuba (1810-1870)
}

\author{
Adriana Chira \\ Emory University (Estados Unidos) \\ adriana.chira@emory.edu
}

\begin{abstract}
Resumen
A través de varios casos judiciales de Santiago de Cuba, exploramos el modo en que los esclavizados trataron de ampliar el significado de la categoría legal "sevicia". Notamos que ese proceso socio-legal y semántico implico juzgar moralmente a los esclavizadores y sus acciones y, a través de ello, incluso a la propia institución de la esclavitud. Históricamente, los esclavistas habían justificado la violencia como un instrumento necesario para controlar a los esclavos, pero en el siglo XIX un número cada vez mayor de personas esclavizadas los llevaron a los tribunales por ello. Algunas de estas demandas iban bastante lejos, reclamando la manumisión por un bajo costo debido a la vejez y enfermedad del peticionario esclavizado. Se suponía que los años de trabajo para el propietario y las dolencias sufridas a lo largo de los mismos servían como una forma de crédito, una reclamación humilde, pero real, de cierta reparación por la esclavitud. Las denuncias de los esclavos a la sevicia culminaron, en ocasiones, en protecciones legislativas adicionales, las más notables de las cuales se incluyeron en las leyes graduales de emancipación de 1870.
\end{abstract}

\section{Palabras Clave}

Esclavitud; emancipación; sevicia; Cuba; historia social; historia legal.

\begin{abstract}
Drawing on judicial cases from Santiago de Cuba, this paper explores how enslaved people have sought to expand the meaning of sevicia throughout the nineteenth century, a process that entailed passing moral judgment on enslavers and their actions, and through it, even on the institution of slavery itself. Historically, enslavers had justified violence as a necessary instrument for controlling enslaved people, but by the nineteenth century enslaved people took them to courts for it in growing numbers. Some such claims went quite far, claiming manumission for a low cost on account of the enslaved petitioner's old age and infirmity. The years spent working for the owner and the infirmities incurred throughout were supposed to serve as a form of credit-a humble, yet, nevertheless, real claim to some reparation for enslavement. Enslaved people's claims to sevicia culminated, on occasion, in additional legislated protections, the most notable of which were embedded in the gradual laws of emancipation of 1870.
\end{abstract}

Esta obra está sujeta a la Licencia Reconocimiento-NoComercial-CompartirIgual 4.0 Internacional de Creative Commons. http://creativecommons.org/licenses/by-nc-sa/4.0/ 


\section{Adriana Chira}

\section{Keywords}

slavery, emancipation, Cuba, violence and torture, legal history, social history.

A principios de la década de 1860, en Santiago, en el oriente de la isla de Cuba, colonia de España, las personas esclavizadas acudían a la oficina del gobernador provincial para solicitar la libertad y la protección contra los esclavistas violentos con creciente celeridad. En general invocaban dos motivos principales. Muchos afirmaban que ya habían pagado por su libertad en efectivo o en servicios, pero que sus dueños se habían negado a expedirles una carta de manumisión (Chira, 2018). Un número cada vez mayor de peticionarios se quejaba también de que sus esclavizadores los habían sometido a una violencia excesiva (sevicia), y que por ello se les debía permitir cambiar de dueño o comprar su libertad a un precio relativamente bajo. Este tipo de acusaciones contra los esclavistas violentos, objeto de este trabajo, no eran en absoluto nuevas, y trataban al Estado como un protector. De hecho, los esclavos que las formulaban recurrían a una política incluida en el compendio legal del siglo XIII, fundamento de la institución de la esclavitud en las colonias españolas de las Américas y en el periodo de transición a la independencia durante el siglo XIX, Las Siete Partidas. ${ }^{1}$ De acuerdo con ella, las personas esclavizadas podían acudir a un juez si su dueño las trataba con excesiva violencia, o si las hacía pasar hambre y no les daba ropa y alojamiento adecuados. Sin embargo, en la primera mitad del siglo XIX se produjeron dos cambios en la forma en que las personas esclavizadas enmarcaban sus demandas de protección corporal. Al igual que en la mayoría de las demandas de libertad, este tipo de reclamos proliferaron, lo que sugiere que los esclavos se volvieron más conscientes de sus derechos, más capaces de acceder al sistema de justicia y más involucrados en el sistema judicial, al mismo tiempo que el estado mismo estaba experimentando con varios modelos jurídicos de transición de la esclavitud a nuevos régimenes de trabajo (Aguirre, 1995; Barragan, 2021; Candioti, 2015; Chalhoub, 2015; Cowling, 2013; De la Fuente, 2007; Díaz y Meriño Fuentes, 2015; Figueroa y Cosme, 2018; Grinberg, 2001; Premo, 2017; de la Fuente \& Gross, 2020; Hünefeldt, 1994; Scott y Hébrard, 2014; Scott, 1983). ${ }^{2}$

Más aún, las propias definiciones de los esclavos sobre lo que constituía la sevicia se ampliaron, un fenómeno señalado por los historiadores que trabajan en otras sociedades esclavistas de América Latina (Proctor III, 2015; Premo, 2017: 208, 212). Como ha señalado Bianca Premo, estas reivindicaciones de la sevicia plantearon cuestiones sobre la moralidad de la esclavitud y del confinamiento y el castigo asociados a ella, en una época en la que las nociones de las teorías de los derechos naturales eran cada vez más conocidas (2017: 212). En la Era de la Emancipación,

\footnotetext{
${ }^{1}$ El código de Las Siete Partidas, Partida IV, Titl. XXI, law VI (1848).

2 Para un ejemplo que muestra los esfuerzos de los escalvizadores de limitar el acceso de los libertos al sistema judicial en la época de la emancipación gradual, véase Freedom's Captives: Slavery and Gradual EMancipation on the Colombian Black Pacific (Barragan, 2021) y "Commerce in Children: Slavery, Gradual Emancipation, and the Free Womb Trade in Colombia" (Barragan, 2021).
} 


\section{Ampliando los significados de Sevicia: Los reclamos de protección corporal de los esclavos en Santiago de Cuba (1810-1870)}

esta ampliación semántica podría hacer que algunos de los reclamos legales de los esclavos para la protección corporal contra la tortura se asemejaran a propuestas de emancipación gradual.

Algunas denuncias de protecciones eran directas, y sus expectativas eran relativamente modestas. Un tal Juan de la Cruz se quejó de que su dueño le había esposado durante mucho tiempo, infligiéndole heridas profundas. ${ }^{3}$ Una madre, Dolores Andrial, presentó una petición para su hijo, que había sido brutalmente castigado por un administrador de la plantación. ${ }^{4}$ Francisco y Francisco Javier se quejaron de malos tratos en la plantación de Guantánamo donde trabajaban. ${ }^{5}$ Una mujer, llamada Paula, también trabajadora de la plantación, se presentó ante el gobernador por el mismo motivo. ${ }^{6}$ En otra petición, un hombre llamado José describió haber huido de la plantación para presentar una petición contra el administrador que lo había golpeado. ${ }^{7}$ Todos estos solicitantes pidieron que se les permitiera cambiar de propietario.

Algunos llevaron sus reclamos más lejos: se quejaron de los elevados precios por los que se habían tasado sus libertades, a pesar de estar enfermos. Afirmaban que eran demasiado viejos para trabajar, y sus propietarios claramente demasiado crueles para notar el dolor que les causaba la más trivial de las tareas. En sus peticiones, la vejez contaba como una forma de discapacidad provocada por el trabajo que al final les daba derecho a la libertad. Desde su punto de vista, la esclavitud era una situación temporal en la vida y la libertad o un precio de manumisión menor constituía una reparación por la violencia que habían soportado durante años o incluso décadas de esclavitud. Como una mujer, Josefina Despaigne, argumentó en su petición: cobrar un alto precio de libertad a alguien en su situación no era "humanitario", un término que recuerda a la retórica abolicionista. ${ }^{8}$ Llevado a su conclusión lógica, este argumento habría dado lugar a la libertad de todas las personas esclavizadas mayores de cierta edad que pudieran pagar un precio de manumisión bajo.

Este trabajo rastrea las acciones legales de los esclavizados del siglo XIX contra la sevicia y argumenta que reclamos como los de Josefina Despaigne fueron un argumento vernáculo y poco conocido para la reparación de la esclavitud en esta sociedad esclavista del Caribe. En la década de 1860, cuando las peticiones de

\footnotetext{
3 "Expediente relativo a la queja producida por el negro Juan de la Cruz de Dn Estansilao Figueroa", 15 de mayo de 1862. Archivo Histórico Provincial de Santiago de Cuba [AHPSC], Gobierno Provincial [GP], leg. 559, exp. 18.

4 "Expediente relativo al castigo del esclavo de D. José Francisco Garcia”, 15 de abril de 1862. AHPSC, GP, leg. 559, exp. 19.

5 "Trata de la prisión del mulato Francisco y del negro Francsico Javier, esclavos de D. Luis Bombu, procedentes de Guantánamo, los cuales se quejan de maltrato", 1865. AHPSC, GP, leg. 560, exp. 6.

6 "Trata de la presentación de la negra Paula, esclava de D. Carlos Ducoureau", 13 de abril de 1865. AHPSC, GP, leg. 560, exp. 9.

7 "Sobre quejas de maltrato del negro José, esclavo de D. Antonio Colas", 19 de julio de 1865. AHPSC, GP, leg. 560, exp. 17.

8 "Sobre coartación de la negra Josefina Despaigne", 16 de septiembre de 1867. AHPSC, GP, leg. 561, exp. 25.
} 
protección corporal se multiplicaron en los tribunales de Cuba, durante casi un siglo, los abolicionistas de élite de todo el mundo atlántico habían señalado las desfiguraciones y mutilaciones de los cuerpos de las personas esclavizadas para criticar la trata y la esclavitud y para despertar sentimientos humanitarios entre el público metropolitano. ${ }^{9}$ Algunos de los propios gobiernos coloniales se habían movilizado para restringir el poder soberano de los esclavistas abriendo nuevas vías para que las personas esclavizadas presentaran demandas contra los propietarios violentos, aplicando medidas de protección que habían sido letra muerta, y haciendo que los propietarios fueran responsables de las personas que liberaban, si esas personas ya no podían valerse por sí mismas. ${ }^{10}$ En el Imperio español, los esclavizados habían tenido históricamente más acceso a las vías legales y el Estado se había involucrado más en limitar los poderes de los esclavistas. Pero incluso allí, las protecciones y los medios para acceder a ellas se multiplicaron también, al menos en teoría, a partir de finales del siglo XVIII. El objetivo aquí, como en otros lugares, era centralizar el control del Estado sobre los medios de violencia, especialmente a partir de finales del siglo XVIII.

En comparación con las mucho más conocidas acciones abolicionistas u oficiales dirigidas por las élites para reducir la tortura y la mutilación de las personas esclavizadas, las demandas legales contra la violencia corporal, como las de Juan de la Cruz, Dolores Andrial, Francisco, Josefina Despaigne o Francisco Javier, podrían parecer una búsqueda relativamente humilde de alivio individual. También parecen ser menos radicales, porque estos solicitantes reclamaban reparaciones y alivio a través de un marco legal colonial. Es probable que los solicitantes conocieran las corrientes abolicionistas que atravesaban las sociedades vecinas, como sugiere la petición de Josefina Despaigne. Pero también elaboraron sus estrategias a partir de los pocos recursos que tenían a su disposición de forma más inmediata y menos

\footnotetext{
${ }^{9}$ Durante la primera fase de la Amelioración, los abolicionistas del Imperio Británico abogaron por políticas diseñadas para hacer que la esclavitud fuera menos destructiva físicamente y también por apoyar tasas de natalidad más altas entre los esclavizados (como solución económica para el fin del comercio de esclavos) (Browne, 2017; Turner, 2017; Hunt-Kennedy, 2020: 3-4). Esto significaba también que los cuerpos de los esclavizados y sus discapacidades se exponían cada vez más a través de descripciones visuales y textuales para argumentar moralmente la necesidad de una reforma y convencer al público metropolitano de la rectitud de la causa abolicionista.

10 Slave No More: Self-Liberation before Abolitionism in the Americas puede consultarse para la introducción gradual de estas protecciones en los diferentes imperios europeos, a partir de finales del siglo XVIII (Helg, 2019: capítulo 9). Además, en el Imperio francés, el Code Noir de 1685 incluía protecciones contra la violencia excesiva de los esclavistas, pero los esclavizados no tenían acceso a vías para aplicarlo. Para un enfoque global de los intentos de centralizar el poder en los imperios europeos del siglo XVIII, reduciendo el número de jurisdicciones, incluso reduciendo la autoridad que los esclavistas tenían sobre los esclavizados, véase Rage for Order: The British Empire and the Origins of International Law, 1800-1850 (Benton \& Ford, 2016). Sobre el uso de la violencia espectacular para controlar a los esclavizados y las justificaciones de los propietarios de plantaciones de que la tortura era una herramienta de extracción de pruebas que podían utilizar en sus propias propiedades (es decir, que el uso de la tortura no se limitaba al aparato judicial del Estado), véase "Prosecuting Torture: The Strategic Ethics of Slavery in Pre-Revolutionary Saint-Domingue (Haiti) (Ghachem, 2011), The Reaper's Garden: Death and Power in the World of Atlantic Slavery (Brown, 2008) y Between Fitness and Death (Hunt-Kennedy, 2020).
} 


\section{Ampliando los significados de Sevicia: Los reclamos de protección corporal de los esclavos en Santiago de Cuba (1810-1870)}

arriesgada. Por ejemplo, habían aprendido cómo funcionaba la valoración del mercado y cómo afectaban sus habilidades o discapacidades particulares a su precio de mercado, algo que sabía la mayoría de las personas esclavizadas que vivían en sociedades en las que la manumisión a través de la autocompra era legal. Además, también sabían lo suficiente sobre las protecciones estatales y sobre las regulaciones del mercado de esclavos: algunos consiguieron acudir a los tribunales o al gobernador si habían sido maltratados; $y$ algunos recurrieron a las oficinas del consejo municipal para aclarar su verdadero valor, cuando no estaban de acuerdo con el propietario.

La historia de estas peticiones de protección corporal es también muy local y centrada en el individuo, otra razón por la que es menos visible en los archivos del abolicionismo. Estudiosos de las reparaciones, como Ana Lucia Araujo, han demostrado que las peticiones de reparación no son un fenómeno reciente. Las personas anteriormente esclavizadas en el mundo atlántico presentaron tales demandas cuando la esclavitud aún era legal o inmediatamente después de su fin. La primera solicitud conocida fue la de una mujer nacida en África, Belinda Sutton, que pidió en 1783 en Masachussets que se le pagara una pensión anual del patrimonio de su antiguo propietario fallecido por haber contribuido a su riqueza con su trabajo (Araujo, 2017: 49-51; Finkenbine, 2007). ${ }^{11}$ Las demandas y peticiones que los esclavizados presentaron para reclamar reparaciones por sevicia pedían mucho menos que Belinda Sutton en el Massachusetts de finales del siglo XVIII. Los solicitantes de Santiago no pidieron que se les devolviera el dinero ni señalaron la riqueza que su trabajo había contribuido a crear. Hicieron algo menos radical: todavía reconocieron que el esclavista tenía derecho a recibir de ellos un precio de manumisión (aunque menor), un reconocimiento que sugiere que no desafiaron plenamente las nociones de valor incrustadas en el mercado de esclavos. Sin embargo, precisamente porque sus reclamos podían parecer relativamente triviales y poco peligrosos (a los ojos de las autoridades), las peticiones y demandas proliferaron, y los peticionarios y litigantes compartieron estrategias $\mathrm{y}$ conocimientos entre sí y con otros, lo que sugiere que sus acciones legales no eran tan individualistas después de todo. Su esfuerzo tuvo efectos acumulativos y fue, como tal, un esfuerzo colectivo, conscientemente o no. Algunos aprovecharon el éxito de sus predecesores para ofrecer definiciones siempre nuevas y ampliadas de la sevicia -sus significados, localmente específicos e incrustados en la costumbre, más que en el derecho positivo, y como tal, de nuevo, menos visibles a los ojos de los historiadores que no acudieran a los archivos provinciales. Esta situación no era anómala, sino que reflejaba la pervivencia de un derecho de Antiguo Régimen que se nutria de múltiples órdenes normativos, y en el cual el arbitrio del juez no era la

11 El texto completo de la primera petición también está disponible aquí: https://royallhouse.org/belinda-suttons-1783-petition-full-text/_Para otras solicitudes de reparación que se produjeron a finales del siglo XIX, véase_My Face Is Black Is True: Callie House and the Struggle for Ex-Slave Reparations (Berry, 2005). 
excepción: el definía lo que era la justicia. En otras palabras, se trataba de una justicia de jueces y no de leyes (Agüero, 2006; Chira, 2021; Hespanha, 1992; Herzog, 2004; Premo, 2017; Tau Anzoátegui, 1992; Vallejo, 1992).

Cuando tomamos a humildes peticionarios como Juan de la Cruz, Dolores Andrial, Francisco o Francisco Javier como referentes en las historias de los reclamos de reparaciones, podemos ir más allá de una imagen de las personas esclavizadas como víctimas impotentes. Los abolicionistas de élite recurrieron al tópico del individuo esclavizado discapacitado, que necesita ser rescatado, con frecuencia para apaciguar los temores de su público sobre un mundo posterior a la emancipación en el que los afrodescendientes ya no serían controlados mediante la esclavitud. ${ }^{12}$ El propio tópico también asignaba un papel especial a los propios abolicionistas, como eje entre los esclavizados y las instituciones políticas. Pero las acciones legales aquí descritas sugieren que, a nivel local y menos visible, los esclavizados de algunas zonas del Imperio español habían desarrollado un discurso de reparación por sus propios medios a través de los marcos institucionales disponibles. Algunas de sus definiciones de protección corporal se desarrollaron de forma gradual, influeyendo las leyes de emancipación gradual.

\section{Santiago de Cuba y la institución de la esclavitud}

En la Cuba decimononica, la mayor productora azucarera del mundo, un espacio plantacionista, los tribunales no eran fácilmente accesibles para las personas escavizadas. Pero Santiago de Cuba ocupaba un espacio distintivo en la geografía político-económica de la isla y del mundo atlántico, lo que también explica por qué las personas esclavizadas, muchas de ellas residentes en zonas rurales, recurrían al sistema de justicia en busca de alivio. Santiago pertenecía a una geografía afrodescendiente alternativa, demasiado tiempo olvidada en la historiografía a favor de la experiencia de la esclavitud en las zonas económicas de extracción y de la experiencia de libertad en los puertos atlánticos urbanos. ${ }^{13}$ Vastas franjas de la América Latina del siglo XIX estaban formadas por comunidades rurales de personas de color libres y liberadas que vivían en áreas inmediatamente adyacentes a las

\footnotetext{
12 Los abolicionistas británicos en Cuba hacían hincapié en la violencia de la esclavitud de las plantaciones como forma de socavar la afirmación de los hacendados de que la esclavitud española era menos brutal. Uno de estos relatos abolicionistas que se centra en la incapacidad de los esclavizados es la obra de 1849 de Richard Madden, The island of Cuba: Its resources, progress, and prospects considered in relation especially to the influence of its prosperity on the interests of the British West India Colonies.

${ }^{13}$ Los investigadores se han centrado principalmente en las plantaciones de azúcar en Cuba. Una obra clásica es la de Manuel Moreno Fraginals, El ingenio: complejo económico-social cubano del azúcar (1978). Una pieza reflexiva que considera cómo el ascenso del azúcar ha moldeado la escritura de la historia dentro de Cuba, con la mayoría de las categorías de análisis que surgen del estudio de las plantaciones de azúcar, es la publicada por Alejandro de la Fuente, "Apuntes sobre la historiografía de la segunda mitad del siglo XVI cubano" (1988). Estudiosos han elaborado sobre la búsqueda de libertad en mundos urbanos del Atlantico, sobre todo en espacios portuarios, pero no solamente, véase, entre otros, Cañizares-Esguerra, Childs \& Sidbury, 2016; Jones, 2018; Stewart \& Marks, 2018. Sobre Santiago de Cuba, véase también, Belmonte, 2011.
} 


\section{Ampliando los significados de Sevicia: Los reclamos de protección corporal de los esclavos en Santiago de Cuba (1810-1870)}

zonas de extracción donde ellos mismos podían haber sido esclavizados o donde aún tenían familia. Un alcance atenuado del Estado y un gran número de personas libres de color y de personas parcialmente manumitidas (individuos que habían pagado una parte de su precio de manumisión) eran los rasgos que definían estas geografías. Las poblaciones libres y parcialmente manumitidas podían ayudar a los esclavizados con recursos y conocimientos institucionales, pero también podían servir como fuente de inspiración y de derecho a la libertad. ${ }^{14}$ Durante el siglo XIX, en Santiago de Cuba, la población libre de color constituía entre el 25 y el $40 \%$ de la población total, su tamaño relativo era mucho mayor que el de su contraparte en la región de La Habana (donde se situaba en torno al 18\% durante el mismo período) (Vives, 1829; O’Donnell, 1847; Comisión Estadística, 1864).

Aunque esta provincia oriental había sido una de las primeras en ser colonizada por los europeos a principios del siglo XVI, su importancia estratégica disminuyó rápidamente una vez que La Habana se convirtió en el principal puerto oficial de la isla, después de 1560. Con el despegue de la economía azucarera hacia la década de 1740, y especialmente después de 1791, las inversiones inundaron la región de La Habana y sus zonas adyacentes (Fradera 2005; Fraginals 2014[1978]; Schneider, 2015 y 2018). A largo plazo, la economía del este estaba dominada por la ganadería (en Puerto Príncipe) y el tabaco en otras partes (Portuondo Zúñiga, 1996 y 2012). Pero también hubo algunas explotaciones de cobre, que pasaron por dos breves fases. La primera, entre la última década del siglo XVI y mediados del XVII, tuvo un impacto social duradero. La extracción de cobre fue la principal actividad económica que atrajo a los comerciantes de esclavos a esta zona. Sin embargo, en 1670, cuando la industria decayó, la Corona española, que tenía plenos derechos de propiedad sobre ellas, anuló el contrato que había concedido derechos de usufructo al agente local que extraía el mineral. La tierra, las minas y la gente esclavizada que trabajaba en ellas pasaron a pertenecer a la Corona (Díaz, 2000: 33). El estatus legal de esta comunidad de 271 personas esclavizadas que ahora pertenecían a la Corona era ambiguo. No estaba definido por el derecho positivo. Más bien, los propios esclavizados definieron sus derechos a través de una combinación de litigios, negociaciones y fugas masivas, cuando las élites de terratenientes locales les amenazaban. Obtuvieron el derecho a no ser puestos a trabajar en La Habana, lejos de sus familias, o a no ser vendidos; obtuvieron el acceso a la tierra y a comprar ellos mismos su libertad a un precio menor que su precio de mercado. En 1800, como resultado de sus continuas peticiones y presiones, la Corona finalmente concedió la libertad a toda la comunidad, que ya contaba con 1065 personas, así como el acceso a la tierra. ${ }^{15}$ El ejemplo de los cobreros, de confiar tanto en el cimarronaje como en

\footnotetext{
14 Otras zonas similares podrían encontrarse en Puerto Rico, la República Dominicana, las tierras bajas del Pacífico de Colombia, en zonas limítrofes con el cinturón del café en el sureste y en la Amazonia en Brasil (Carrasquillo, 2006: capítulo 1; Gudmundson \& Wolfe, 2010; Mattos, 2013; Eller, 2016; Cañizares-Esguerra, Childs \& Sidbury, 2016; Leal, 2018; De la Torre, 2018; Jones, 2018; Stewart \& Marks, 2018).

15 La Real Cédula se publicó el 7 de abril de 1800. La versión impresa aparece en la obra de José Luciano Franco, Las minas de Santiago del Prado y la rebelión de los cobreros, 1530-1800 (1975).
} 


\section{Adriana Chira}

el sistema judicial para ampliar sus derechos, probablemente inspiró a otras personas esclavizadas que vivían aquí, dándoles una conciencia de derecho similar que los cobreros habían logrado asegurar para sí mismos. Cuando se inició un segundo auge del cobre en torno a la década de 1830, seguía estando muy concentrado en El Cobre, estaba en manos de inversores ingleses y dependía de la mano de obra de 800 personas esclavizadas. ${ }^{16}$

Durante el siglo XIX, la mayoría de los esclavos que vivían en las zonas rurales de los alrededores de Santiago trabajaban en plantaciones de café. Algunas plantaciones de azúcar poco mecanizadas marcaban el paisaje en las afueras de Santiago, mientras que otras se desarrollaron en la década de 1850. Pero la región era conocida principalmente por su producción de café. El auge del café, que se produjo en dos etapas, se extendió por la zona a partir de 1791, cuando algunos refugiados de Saint-Domingue invirtieron en tierras y en la esclavitud de la zona. Si bien los refugiados fueron expulsados en 1809, algunos miembros de la élite más alta regresaron después de 1815, deseosos de dar un nuevo impulso a las plantaciones de café a la luz de los altos precios del café en los mercados mundiales (Portuondo Zúñiga, 1993; Renault, 2012 ; Chira, 2016). Durante este segundo momento, los refugiados transformaron profundamente esta región. Trajeron un número sin precedentes de cautivos africanos a esta zona, principalmente a través de las redes de contrabando. En 1827, cuando el café estaba en su apogeo económico, la mitad de la población estaba sometida a la esclavitud (Vives, 1829). Sin embargo, la crisis económica no tardó en llegar, y con ella las altas tasas de manumisión. Aunque algunos hacendados vendieron a los esclavizados que tenían a su alcance a las plantaciones de azúcar del centro-oeste de Cuba, la mayoría trató de obtener beneficios permitiendo que los esclavizados se compraran a sí mismos (Chira, 2016: cuadro 2,154). Este acuerdo habría sido rentable a nivel local, ya que muchos de los que compraron su libertad eran mujeres y niños, y los hacendados de azúcar del oeste no estaban tan interesados en ellos. Gracias a la manumisión, una clase de afrodescendientes rurales libres llegó a dominar la región demográficamente, una peculiaridad en la isla. Esta clase tenía vínculos familiares con los esclavizados, algunos de los cuales seguían trabajando en las pocas plantaciones que quedaban, y en ocasiones incluso les ayudaban a conseguir su libertad. Aunque algunas personas libres de ascendencia africana eran propietarias de personas esclavizadas, la probabilidad de que lo fueran entre los pequeños propietarios disminuyó a medida que avanzaba el siglo y el precio de la mano de obra esclava subía. Los cobreros con derecho y sus descendientes, el campesinado afrodescendiente libre de gran importancia demográfica, una élite relativamente débil y fragmentada, y un panorama que reducía el poder policial de la élite crearon algunas posibilidades dentro de los tribunales para los que seguían sometidos a la esclavitud. Algunos de

16 "Expediente sobre las minas de cobre de la Isla de Cuba," Archivo Histórico Nacional [AHN], Ultramar, leg.6, exp. 4. 


\section{Ampliando los significados de Sevicia: Los reclamos de protección corporal de los esclavos en Santiago de Cuba (1810-1870)}

los funcionarios municipales preferían atender las demandas de libertad a organizar campañas anti-cimmaronas o investigar conspiraciones de esclavos.

\section{El derecho positivo y sevicia}

Las Siete Partidas del siglo XIII, el principal cuerpo de derecho positivo que regulaba la institución de la esclavitud en la América española, ofrecía algunas protecciones a los esclavos contra la violencia de los propietarios. El texto establecía que las personas esclavizadas podían acudir a los jueces en busca de protección cuando los esclavistas les hicieran daño excesivo o les hicieran pasar hambre. Si se les declaraba culpables, los propietarios debían vender a los esclavos a otro dueño. ${ }^{17}$ La medida también redujo el poder de los esclavistas sobre los esclavos: los esclavistas eran responsables de sus actos ante el Estado y, como vasallos, los esclavizados podían acudir a varios ramos del sistema judicial del Estado en busca de protección (Bennett, 2005; Bennet, 2018: 42; McKinley, 2016). Varias órdenes reales perfilaron las oportunidades judiciales disponibles para las personas esclavizadas (al menos en teoría) a través de las cuales podían acceder a la esfera legal: desde la reparación legal expedita hasta la representación legal gratuita o casi gratuita contra los esclavizadores. En la Cuba del siglo XIX, dicha representación se daba a través del cargo de síndico procurador, que era ocupado por un miembro del ayuntamiento de forma rotativa. Para acceder a estos servicios, los esclavos debían presentar una petición, y solo los que se consideraba que tenían una causa legítima de acción podían pasar al litigio (Bermúdez Aznar, 1980; Borah, 1983: 13-14; González Undurraga, 2012; Hernández, 2014; Perera Díaz \& Meriño Fuentes, 2015: 1:153; Rebagliati, 2017). ${ }^{18} \mathrm{Al}$ facilitar a los esclavos el acceso a las instituciones estatales, la Corona también intentaba liberar las tensiones sociales y esperaba desalentar la búsqueda extrajudicial de la libertad (mediante la insurgencia o el cimarronaje). Por supuesto, estas protecciones planteaban problemas. No definían muy claramente lo que significaba realmente la violencia excesiva, dando a los jueces, que podían tener intereses creados en la protección de la élite de esclavistas, poderes discrecionales sobre el significado del término. El segundo problema era la aplicación: las personas esclavizadas debían encontrar un juez por sí mismas, una tarea especialmente desalentadora dada su condición legal y sus condiciones de vida (que implicaban diversos grados de confinamiento). Además, tenían que arriesgarse a empeorar una relación ya tensa — si perdían, tendrían que volver a la custodia de su dueño. ${ }^{19}$

\footnotetext{
17 El código de Las Siete Partidas, Partida IV, Titl. XXI, law VI (1848).

18 Novísima Recopilación de las Leyes de España, Libro V, Tit. I, Leyes 29 y 30, 2:348 (1805).

19 Mientras se resolvía el caso, se ponía a los esclavos al cuidado del Estado a través del depósito judicial para garantizar que no fueran castigados por propietarios vengativos. Al principio, estos depósitos eran particulares que acogían a los esclavos mientras duraba la acción judicial a cambio de su trabajo. A partir del 18 de abril de 1840, el Estado creó un depósito público. Los esclavos que litigaban por su libertad o contra los esclavistas violentos eran puestos bajo su jurisdicción. Se les
} 
La legislación protectora proliferó (en el sentido de que gran parte de ella se reiteró) especialmente a partir de las Reformas Borbónicas. Pero su contenido incluía pocas innovaciones radicales respecto a las medidas contenidas en Las Siete Partidas. En 1789, la Corona abrió el comercio de esclavos a las Américas, en respuesta a las presiones de los oligarcas azucareros de Cuba. Por temor a que la afluencia de un número sin precedentes de cautivos provocara disturbios en la isla, la Corona acompañó la entrada del comercio de esclavos con protecciones para los mismos, que se incluyeron en la Instrucción sobre educación, trato y ocupación de los esclavos. Ahora, además de garantizar el derecho a ser visto por un juez, la Corona se encargó de enviar delegados a las propiedades rurales para comprobar las condiciones en que se encontraban los esclavos (Lucena Salmoral, 2000: 1155, esp. art. XIII). Esto habría facilitado el acceso de los esclavos al sistema legal. Pero los esclavistas de Cuba y Venezuela se opusieron con vehemencia, señalando que, al hacer que los esclavos se sintieran con derechos, las medidas eran más propensas a fomentar el descontento que a sofocarlo. Sus argumentos se impusieron y la Corona suspendio los efectos al no publicarla, encargando, en cambio, los tribunales americanos actuar conforme al espíritu de sus artículos (Lucena Salmoral, 1996; Portuondo Zúñiga, 2010: 47-49). ${ }^{20}$ En Santiago, el más vehemente defensor de esta Instrucción fue un concejal llamado Nicolás Pérez Garvey, también ardiente promotor del minifundio y del cultivo del tabaco; el cual probablemente vio en este documento la oportunidad de aumentar las tasas de manumisión y de mermar el poder de la élite esclavista. Sin embargo, no hay constancia de que los funcionarios del Estado acudieran a las propiedades rurales para comprobar las condiciones en las que se encontraban los esclavos. La mayoría de las peticiones y demandas contra la sevicia se presentaron por iniciativa de los esclavos, lo que sugiere que, aunque la medida se mantuvo a nivel local, una de sus principales innovaciones no se aplicó.

Para las personas esclavizadas, la dificultad para definir la sevicia dentro de la corte provenía del trato diferenciado al que la ley las sometía. Históricamente, los juristas y los clérigos habían considerado que este sector era más propenso a cometer excesos de conducta que otros grupos sociales y, por tanto, merecía un castigo más estricto. Por ejemplo, la Corona había establecido protecciones mucho más amplias para las poblaciones indígenas de toda América que para los esclavos. Las primeras leyes aprobadas en América, en lugares como Santo Domingo, incluían una vigilancia más violenta de los esclavos y de los afrodescendientes libres (considerados enemigos de guerra). Incluso la conversión al cristianismo debía incluir algún elemento de fuerza cuando se aplicaba a los esclavizados, considerado en el mejor interés de los convertidos (Brewer-García, 2020: esp. 64-73). Por lo tanto, parte de la violencia fue sancionada por el Estado.

puso a trabajar y se esperaba que entregaran sus ganancias al Estado (Perera Díaz \& Meriño Fuentes, 2015: 1:180-198, esp. 189).

20 "Statement from the Havana ingenio owners to the king", 18 de enero de 1790 (García Rodríguez, 2011: 55-73). 


\section{Ampliando los significados de Sevicia: Los reclamos de protección corporal de los esclavos en Santiago de Cuba (1810-1870)}

Pero si las leyes daban cabida a cierto grado de violencia, seguían siendo imprecisas en cuanto a la cantidad que se justificaba. Algunos esclavos vieron una oportunidad en esta ambigüedad y presionaron al sistema de justicia para que los aliviara. En parte como respuesta a estas presiones desde abajo, a lo largo de la primera mitad del siglo XIX, el Estado se volvió cada vez más preciso sobre el grado y los métodos de castigo que se podían aplicar. Pero, a través de estas políticas, los responsables del Estado español también trataron de aplacar a los abolicionistas británicos que habían estado vigilando de cerca a Cuba, especialmente por el incumplimiento de los hacendados del tratado de 1817 para abolir el comercio de esclavos con la isla. La clase hacendada había defendido sus inversiones en la esclavitud alegando que, como parte de la sociedad y la cultura españolas, trataban a los esclavizados mejor que sus homólogos anglosajones. Los abolicionistas británicos recorrieron la isla recogiendo pruebas de lo contrario y publicándolas. ${ }^{21}$ La introducción de más protecciones para los esclavos fue una forma de responder a estas críticas abolicionistas, pero también, de nuevo, de mellar parte del enorme poder que los hacendados cubanos habían ido amasando (la isla se había convertido en el mayor productor de azúcar para los mercados mundiales en 1820).

El Reglamento de esclavos, publicado el 14 de noviembre de 1842 y puesto en vigor a partir del 1 de enero de 1843, fue un intento por parte de la principal autoridad de la isla (el capitán general, al tiempo Gerónimo Valdés) de introducir protecciones que vigilaran mejor a una población esclavizada y revuelta (Cano \& De Zalba, 1875: 20-32). Las autoridades expresaron su descontento con el creciente número de fugitivos a lo largo de la década de 1830 (Duharte Jiménez, 1988). En 1841, reprimieron tres momentos de disturbios al oeste de Cuba (Lovejoy, 2018). Los temores de que los abolicionistas británicos y haitianos avivaran el descontento entre los esclavos de las plantaciones de la isla se dispararon: los esclavistas veían la insurrección en cada esquina. ${ }^{22}$ El 23 de febrero de 1842, el capitán general envió una serie de preguntas a los principales hacendados de la isla para recabar información para una política local destinada a reducir la probabilidad de tales disturbios. Su objetivo era reconocer algunos derechos a los esclavos y, al mismo tiempo, convencer a los esclavistas de que los aceptaran.

\footnotetext{
${ }^{21}$ Madden (1849) ayudó a publicar la única narración de esclavos escrita mientras la esclavitud era una institución (Manzano, 1996; Finch, 2015; Paquette, 1988).

22 "Real Orden fecha Madrid 14 marzo 1837 'Para privar que se internen emisarios de los que trabajan en las posesiones vecinas por la insubordinación de la esclavitud'", leg. 38, exp. 30; "Expediente promovido con motivo de la entrada en el puerto de Manzanillo de la balandra haitiana Tenelón", 18 de mayo de 1841, leg. 136, exp. 17; "Sobre la comisión dada por el gobernador de Cuba a D. Ramón Arango para adquirir noticias de Haití", 17 de mayo de 1841, leg. 136, exp. 26; "Comisión a un confidente para pasar a Jamaica a averiguar sobre proyectos de insurreccionar la esclavitud de esta Isla de Cuba", 8 de abril de 1843, leg. 41, exp. 52; "Autos seguidos a consecuencia de denuncia dada al Sor Regente de que entre los adornos del escudo real colocado en la parte superior de la puerta principal del palacio de la real audiencia se divisaba de un lado la bandera de la república de Haití y al otro lado la de Colombia", 4 de noviembre de 1843, leg. 41, exp. 62. Archivo Nacional de Cuba [ANC], Asuntos Políticos [AP].
} 


\section{Adriana Chira}

El Reglamento de esclavos, que formaba parte de un bando de gobierno de tres partes diseñado para mejorar la vigilancia en la isla, casi no incluía ninguna innovación legal, salvo una mención a la coartación que la formalizo (de la Fuente, 2007). Los autores se inspiraron en un documento similar que se había aplicado en Puerto Rico en 1826 y en la Instrucción de 1789 (Lucena Salmoral, 2000: 433). Su intención, sin embargo, era asegurar que esta vez los esclavistas de Cuba aceptaran algunas de las protecciones, incluso si eso significaba renunciar a parte de su poder. El documento regulaba la cantidad de comida, ropa y tiempo a la que tenían acceso los esclavos, así como los tipos de disciplina que podían utilizar los esclavistas. Los artículos 41 a 47 establecían que los esclavistas podían castigar físicamente a los esclavos dentro de ciertos límites, a menos que estos hubieran cometido un delito grave, en cuyo caso las instituciones estatales se encargarían del castigo. Si el propietario o su agente superaban los límites permitidos, debían ser multados y, en algunos casos, denunciados y llevados ante un juez. Los expertos médicos debían comprobar los síntomas físicos de los demandantes y decidir si eran debilitantes. El Estado podía obligar al propietario a vender a la persona esclavizada, y si esta quedaba incapacitada, el propietario tenía que pagar su mantenimiento (Tardieu, 2003). ${ }^{23}$ Los efectos de este Reglamento fueron limitados. Mientras que el artículo 48 ordenaba que los jueces locales (pedáneos) entraran en las propiedades rurales para garantizar el cumplimiento de las medidas incluidas en él, una de las secciones posteriores del Bando de policía, la Instrucción de pedáneos, les prohibía tales acciones (Lucena Salmoral, 2000: 433). El 31 de mayo de 1844, el nuevo capitán general de la isla, Leopoldo O'Donnell, admitió que la cantidad de comida y ropa que los hacendados concedían a los esclavos era una cuestión de costumbre y que era mejor dejarla en manos de los propios hacendados, eliminando de hecho al Estado de la relación entre esclavistas y esclavizados en este asunto (Lucena Salmoral, 2000: 434).

Documentos como la Instrucción de 1789 y su sucesor de 1843, el Reglamento, ocultan, sin embargo, el impacto dinámico que los litigios y las peticiones de los esclavos podían tener en el Estado. Dichos litigios podían conseguir gradualmente derechos para los esclavizados de forma individual, en ausencia de legislación. En ocasiones, esos derechos individuales se convirtieron en legislación. Pero el poder del derecho positivo sobre la adjudicación de estos casos siguió siendo relativamente limitado. Las demandas de protección de las personas esclavizadas contra la sevicia se basaban en la reputación local y en el capital moral (de los propietarios y de los esclavos). El proceso legal iba más allá de la recogida de pruebas de los cuerpos de los esclavos. De hecho, el estado de esos cuerpos se convertía en un teatro sobre el que los propios esclavistas eran sometidos a un juicio moral, en formas que excedían los principios del derecho positivo. La dinámica de

23 "Reglamento de esclavos", 14 de noviembre de 1843 (Cano \& De Zalba, 1875: artículos 41-47, páginas 30-32). 


\section{Ampliando los significados de Sevicia: Los reclamos de protección corporal de los esclavos en Santiago de Cuba (1810-1870)}

poder y las expectativas morales de la comunidad desempeñaban un papel más importante que el derecho positivo dentro de los juzgados locales.

\section{Litigios y significados de sevicia}

Hay diferentes medios por los cuales los esclavos pueden haber aprendido a desplegar la violencia de los esclavistas contra ellos. Es posible que conocieran el proceso legal que les ofrecía protección a través de otras personas que han pasado por él. Ademas, cuando se encontraban en las zonas rurales, los familiares o amigos libres de la ciudad podían apoyar ocasionalmente sus esfuerzos legales. Por ejemplo, en 1811, Luisa Montaña se presentó ante el síndico procurador para reclamar que había sido excesivamente castigada por su dueño; es probable que haya recibido alguna ayuda de su marido libre. Los médicos describieron profundas heridas ulceradas, que achacaron a los repetidos azotes, y una importante pérdida de sangre. El jefe de la policía explicó que la crueldad con la que se había tratado a la esclava "no era justificable, y excedía los derechos de un esclavista, así como toda forma de sensibilidad humana" ("carnicería hecha en la cierva exedente a la podestad dominica y a toda sensibilidad humana"). Claramente lanzaba una acusación moral contra el propietario y, de paso, sugería que la esclavitud podía causar daños físicos al esclavizado y daños morales al esclavizador, que había perdido toda su "sensibilidad humana".

Como en este caso, afirmaciones como la de Montaña y del jefe de policia, ciertamente perjudicaban la reputación pública de los esclavistas, que a menudo consideraban que debían defenderse y afirmar que en realidad eran justos disciplinadores. Ante el juez, el propietario, un tal Luis Gerbet, explicó que Montaña "padec[ia] los vicios de ladrona, cimarrona, borracha pidiendo plata a los conocidos del exponente, y aun limosna en descredito de su [de Gerbet] buena fama". Montaña estaba casada con un hombre libre de color; cuando huyó, lo hizo para ver a su marido, un derecho que tenían los esclavos, pero que Gerbet se negó a reconocer. El tribunal se puso de parte de Montaña, a quien se le permitió buscar otro dueño, y obligó a Gerbet a pagar todos los gastos del juicio. ${ }^{24}$ Es probable que el marido le proporcionara los recursos para iniciar el caso en primer lugar (mediante la movilidad en la ciudad, y el dinero para pagar la redacción de la petición).

En otro caso, una mujer llamada María Josefa Herrera llegó hasta el gobernador para presentar una petición en nombre de su hijo, que estaba esclavizado en una plantación de café. El hijo se desempeñaba como intendente (administrador de la plantación), y como tal, no era del agrado de los demás trabajadores esclavizados. Cuando estos decidieron huir en masa, fue al hijo de Herrera a quien el hacendado decidió castigar, dejándolo incapacitado. Herrera se dio cuenta de que presentar una

24 "Diligencias promovidas por el Sindico Procurador Gral contra Luis Gerbet [Gervet] por el cruel castigo que dio a su esclava Luisa Montaña", 1811, leg. 606, exp. 13, 897. ANC, Audiencia de Santiago de Cuba [ASC]. 
petición a las autoridades locales del pueblo no serviría de mucho, dado que todos eran amigos del hacendado, así que llevó el caso hasta Santiago. ${ }^{25} \mathrm{Su}$ capacidad de acceso a la ciudad y su movilidad fueron claves para esta petición, así como su conocimiento del sistema judicial. El resultado de esta petición de cambio de titular sigue sin estar claro.

Algunos esclavos trataron de instrumentalizar la violencia que sus cuerpos habían tenido que soportar no en el momento en que se les había infligido, sino más bien para después negociar precios de manumisión más bajos. Comprendían perfectamente que su valor de mercado era menor y que el costo de su libertad debía reflejarlo. Esto sugiere que los esclavos no eran solo objetos del mercado de esclavos. Escuchaban atentamente y prestaban atención a cómo se redactaban las facturas de venta. En estos documentos, los notarios y los peritos médicos hacían constar los "defectos" (o tachas) para asegurarse de que el comprador no ejerciera acciones redhibitorias en un momento posterior. Dichos defectos debían corresponderse con un menor valor de mercado. Es probable que, a través de estos momentos de valoración en el mercado, los esclavos comprendieran algunas de las formas en que podían reclamar algún tipo de alivio por los daños físicos a los que habían sido sometidos. Cuando el esclavizador se negaba a rebajar el precio de la manumisión, algunos esclavos recurrían a los tribunales y a sus expertos en busca de ayuda.

Por ejemplo, en 1825, un esclavo discapacitado llamado Juan Luís acudió a la oficina del síndico procurador para pedir que la ciudad le proporcionara una evaluación oficial de su precio. Su dueño había estimado el precio en 460 pesos, lo que Juan Luís consideraba injusto, ya que no podía mover una de sus manos y sufría repetidos espasmos. Los médicos de la ciudad confirmaron la parálisis de una mano, pero no los espasmos, y redujeron su valor a 250 pesos. ${ }^{26}$ De igual manera, más de una década después, en 1837, la esclava Celestina convenció al albacea testamentario de su difunto dueño para que evaluara de nuevo su precio y lo rebajara alegando que estaba gravemente enferma. Sufría una obstrucción abdominal y una interrupción temprana de la menstruación. Celestina formaba parte de una herencia sobre la que varios herederos estaban en conflicto. No se ponían de acuerdo sobre el precio de su manumisión ni sobre quién sería su nuevo propietario. Celestina intentó tomar su destino en sus manos acudiendo a los tribunales, pero falleció mientras se resolvía su demanda. ${ }^{27}$

Es inevitable preguntarse qué habría significado la libertad legal para una persona esclavizada que había quedado físicamente incapacitada por la esclavitud. ¿Cómo se ganaría la vida Juan Luís, dada su parálisis? Si hubiera sobrevivido a su demanda, ¿cómo habría pagado Celestina los gastos médicos? El Reglamento de 1843 había

25 “Diligencias promovidas por María Josefa Herrera contra D. Jose Fabie por haverle castigado a su hijo José Trinidad quien es esclavo, 1837”, leg 381, exp. 3. AHPSC, Juzgado de Primera Instancia [JPI]. 26 "El Síndico Procurador General, Dn José María Veranes, pide el reconocimiento del negro Juan Luis, esclavo de Dn Miguel Ruíz para su libertad”, 1826, leg. 701, exp. 15, 908. ANC, ASC.

27 "Incidente de la testamentaria del regidor Dn Juan Antonio Bestard sobre la libertad de la esclava Celestina", 1837, leg. 130, exp. 2 418. ANC, ASC. 


\section{Ampliando los significados de Sevicia: Los reclamos de protección corporal de los esclavos en Santiago de Cuba (1810-1870)}

ordenado que los esclavistas fueran responsables de mantener a los esclavos que habían quedado discapacitados. ${ }^{28}$ Pero solo podemos dudar de la eficacia de este mandato. Los casos de Celestina y Juan Luís se presentaron antes de la aprobación del Reglamento. Es posible que tuvieran acceso a familiares libres que hubieran podido proporcionarles algún apoyo. Pero, como sugiere el caso de Celestina, una libertad basada en la manumisión, por la que la persona esclavizada todavía tenía que pagar, podría haber supuesto un alivio para el esclavizador - que obtenía un beneficio del precio de la libertad, al tiempo que no tenía que asumir ninguna responsabilidad relacionada con el cuidado-. Aun así, parece que estas acciones legales tenían un significado importante para los propios peticionarios y litigantes. Aunque podían perder económicamente, probablemente querían disfrutar de la autonomía que la libertad legal les habría otorgado.

Algunos esclavos también utilizaron los litigios y las peticiones para ampliar el significado de sevicia. Argumentaban que no recibían una alimentación y un alojamiento adecuados. Desde Las Siete Partidas, las autoridades habían vinculado históricamente estas dos prerrogativas con la protección contra la violencia excesiva. Pero los litigantes llevaron este reclamo un paso más allá. Invocaron el derecho a trabajar en sus propias huertas (conucos) como base de otro derecho sustitutivo, el de dedicarse a actividades de mercado, otro medio de satisfacer sus necesidades de subsistencia, pero también uno que podría proporcionarles los recursos tan necesarios para pagar su manumisión. De este modo, se ampliaba el derecho a la protección corporal, el ámbito de las actividades y el tipo de autonomía a la que tienen derecho. Este fue el caso de un hombre llamado Gerónimo.

En 1830, Gerónimo presentó una demanda en el juzgado de primera instancia de Santiago en la que reclamaba el derecho a trasladarse a la ciudad. ${ }^{29}$ Gerónimo había trabajado como esclavo doméstico en un hogar urbano durante veinticinco años. El síndico alegó que su comportamiento en la casa de Da Ana Bernabela Montalbán había sido siempre ejemplar. Gerónimo había servido putativamente a Montalbán con "cariño, buena disposición, y si se puede decir gusto". Dijo que su relación había sido tan armoniosa que ella le había concedido mucho tiempo para trabajar por su cuenta, lo que le permitió ahorrar los 200 pesos que utilizó como anticipo para su libertad. Pero, de repente, Montalbán decidió venderlo a su hijo, que tenía una granja de animales en el campo, relativamente lejos de la ciudad, donde había pocas oportunidades de ganar dinero adicional. Gerónimo pidió que se le permitiera volver a la ciudad o trasladarse a un pueblo pequeño donde pudiera encontrar una ocupación que le diera dinero. Su nuevo propietario no consideró aceptable su comportamiento y se quejó al juez de la resistencia de Gerónimo.

\footnotetext{
28 "Reglamento de esclavos" (Cano \& De Zalba, 1875: artículo 46, 31).

29 "Recurso del Síndico Procurador General Dn José Manuel de Zayas en representación del esclavo Gerónimo a consecuencia de la demanda propuesta contra Dn José Joaquín Díaz para que le preste mano a la coartación de aquel, 1830", leg. 1 228, exp. 41 447. ANC, ASC.
} 
Gerónimo perdió su caso en Santiago porque no pudo reunir suficientes testigos que pudieran testificar su buena reputación. Así que, aunque Gerónimo había pagado aproximadamente la mitad de su precio de manumisión, su dueño pudo inclinar los tribunales a su favor. Pero este no era necesariamente el veredicto final, y Gerónimo decidió llevar su caso a la Audiencia de Puerto Príncipe, el tribunal de apelación. Allí, él y su nuevo síndico cambiaron de táctica. Esta vez, invocaron la noción de autoconservación, pero la vincularon a los derechos familiares. El síndico argumentó que Gerónimo estaba casado con una mujer libre. Poder mantenerla y mantenerse a sí mismo requería más tiempo del que le permitía su esclavizador: "Penétrese V.E. contemple por un momento a qué grado de miseria y de desdicha no se verá expuesto un hombre a quien absolutamente se le escasean los medios de subvenir sus obligaciones". El tribunal concedió a Gerónimo el derecho a trabajar en su huerto un día a la semana, una victoria muy pequeña, ya que este era un derecho consuetudinario del que disfrutaban la mayoría de los esclavos. Por lo tanto, la Audiencia se limitó a aplicar una disposición consuetudinaria en lugar de añadir nuevos derechos. Sin embargo, este caso sigue destacando. El síndico ancló un derecho consuetudinario (a un huerto y al tiempo para trabajar en él) a un estatuto existente con Las Siete Partidas que ordenaba la protección corporal. Además, interpretó, aunque sin éxito, la autoconservación de forma más amplia que la hambruna individual —amplió el significado del término para incluir los derechos y el apoyo de la familia-. Una alegación del derecho a la subsistencia tenía más posibilidades de influir en los tribunales, y litigantes como Gerónimo probablemente lo sabían. Pedir otras prerrogativas (como la de apoyo de la familia) bajo el paraguas del derecho a la subsistencia era una estrategia inteligente, con más probabilidades de obtener dividendos que pedir esas prerrogativas a secas.

En ocasiones, los litigios dieron lugar a leyes. Es probable que Gerónimo no fuera el único en pedir el derecho a trabajar un día a la semana en su conuco, lo que finalmente se plasmó en el Reglamento de esclavos de 1843.30 Otra serie de demandas presentadas a cuenta de la sevicia de los propietarios acabó con la esclavitud en la metrópoli. Tomasa Jiménez, María Antonia García y Tomas Bayanza acudieron a los tribunales de Madrid y se quejaron de que habían sido maltratados mientras vivían en la Península Ibérica; fueron llevados allí desde Cuba por sus dueños. Los tribunales se pusieron de su parte y ordenaron que se les permitiera encontrar otro propietario. Pero al parecer, no había mucha gente dispuesta a ser propietaria de esclavos en Iberia en aquella época - los tres no pudieron encontrar a nadie interesado en comprarlos-. En su defensa, sus dueños se quejaron de que cuando traían esclavos de las Antillas, esos individuos dejaban de comportarse de forma obediente, lo que hacía necesario un castigo severo. Sin embargo, cuando ellos, los propietarios, administraban esos castigos, los esclavos podían presentar fácilmente denuncias ante el Estado e infligir multas a sus dueños. En respuesta a estas demandas de libertad, la Corona decidió poner fin a la institución de la

30 “Reglamento de esclavos" (Cano \& De Zalba, 1875, artículo 13, 23). 


\section{Ampliando los significados de Sevicia: Los reclamos de protección corporal de los esclavos en Santiago de Cuba (1810-1870)}

esclavitud en el territorio iberico, aprobando una orden real a tal efecto el 29 de marzo de $1836 .{ }^{31}$

Cuando Juan de la Cruz, Dolores Andrial, Francisco, Josefina Despaigne y Francisco Javier presentaron sus demandas legales, los jueces locales de Santiago eran conscientes de las profundas transformaciones que se estaban produciendo fuera de Cuba. Estados Unidos estaba en plena guerra civil sobre el futuro de la institución de la esclavitud. Más cerca, en la República Dominicana, el campesinado se había levantado en armas contra las fuerzas militares españolas que reocupaban esta república independiente con la intención de volver a esclavizar a la población libre de ascendencia africana. A lo largo de la década de 1860, el campo alrededor de Santiago bullía con rumores de insurgencias antiesclavistas (Maia Mata, 2015). Los hacendados y las autoridades estaban en guardia, incluso cuando probablemente se veían presionados para permitir algunas aperturas para la libertad a través del proceso legal, lo que podría explicar el creciente número de demandas de libertad y peticiones contra los esclavistas violentos.

En 1868, los campesinos locales, los pequeños propietarios y los medianos hacendados y ganaderos se levantaron contra el dominio colonial español. También tenían otros objetivos. La población afrodescendiente, que constituía la mayoría de la insurgencia independentista, también quería una emancipación general inmediata, que los dirigentes blancos acabaron aceptando. En respuesta a la insurgencia, el gobierno español aprobó una ley de emancipación gradual en 1870. ${ }^{32}$ Varias de las medidas incluían respuestas a las demandas que los esclavos habían presentado anteriormente en los tribunales. Se prohibió la flagelación, se declaró libres a los esclavos mayores de 60 años y los esclavistas violentos podían perder totalmente los derechos de dominio sobre los esclavizados. La esclavitud quedó totalmente abolida en Cuba en 1886.

\section{Conclusión}

Las principales conclusiones de este trabajo son una contribución a una amplia historiografía que ha restituido a las personas esclavizadas un papel en el proceso legal más general de abolición de la esclavitud (entre otros, Aguirre 1995; Candioti, 2015; Scott, 1983). Aquí hemos explorado el modo en que los esclavizados trataron de ampliar el significado de la sevicia a lo largo del siglo XIX, un proceso que implicaba juzgar moralmente a los esclavizadores y sus acciones y, a través de ello, incluso a la propia institución de la esclavitud. Históricamente, los esclavistas habían justificado la violencia como un instrumento necesario para controlar a los esclavos, pero en el siglo XIX un número cada vez mayor de personas esclavizadas los llevaron

\footnotetext{
31 "Real Orden declarando libres a los esclavos que se conduzcan a la Peninsula", 29 de marzo de 1836 (1875: 14).

32 "Decreto de abolición de la esclavitud en la forma y bajo las reglas que se expresan", 4 de julio de 1870 (Lucena Salmoral 2000: artículo, 17, artículo 4, San Ildefonso, 1323)
} 
a los tribunales por ello. Asociaban a la sevicia una amplia gama de conductas de los esclavistas, como sugiere el caso de Gerónimo, sabiendo que esta causa particular de acción legal tendría más probabilidades de éxito que otras. Los jueces estaban más dispuestos a escuchar los reclamos de los esclavos en este punto, especialmente en un lugar como Santiago, donde el poder local de los hacendados había sido desafiado por los auges y caídas económicas. Algunas de estas demandas iban bastante lejos, reclamando la manumisión por un bajo costo debido a la vejez y enfermedad del peticionario esclavizado. Se suponía que los años de trabajo para el propietario y las dolencias sufridas a lo largo de los mismos servían como una forma de crédito, una reclamación humilde, pero real, de cierta reparación por la esclavitud y, como tal, una acusación moral a la institución de la esclavitud. Las denuncias de los esclavos a la sevicia culminaron, en ocasiones, en protecciones legislativas adicionales, las más notables de las cuales se incluyeron en las leyes graduales de emancipación de 1870. Sin embargo, la mayoría de estas reivindicaciones seguían siendo asuntos locales. Nunca se convirtieron en derecho positivo, y los jueces las resolvieron basándose en la dinámica de poder local y en el capital moral del propietario y del litigante esclavizado. Es probable que por esta razón estas denuncias puedan parecer pequeñas en relación con los esfuerzos intelectuales-abolicionistas de la época. Pero, aun así, revelan un sentimiento de derecho a las instituciones estatales que persistiría entre los descendientes de estos litigantes hasta bien entrado el siglo XX.

\section{Archivos y fuentes}

Archivo Histórico Nacional [AHN]: Ultramar, leg. 6, exp. 4.

Archivo Histórico Provincial de Santiago de Cuba [AHPSC]

Gobierno Provincial [GP]: (1862) leg. 559, exp. 18, exp. 19; (1865) leg. 560, exp. 6, exp. 9, exp. 17; (1867) leg. 561, exp. 25.

Juzgado de Primera Instancia [JPI]: leg. 381, exp. 3.

Archivo Nacional de Cuba [ANC]

Asuntos Políticos [AP]: (1837) leg. 38, exp. 30, exp. 31; (1841) leg. 136, exp. 17, leg. 136, exp. 26; (1843) leg. 41, exp. 52, leg. 41, exp. 62.

Audiencia de Santiago de Cuba [ASC]: (1811) leg. 606, exp. 13,897; (1826) leg. 701, exp. 15,908; 1837, leg. 130, exp. 2,418; (1830) leg. 1228, exp. 41,447 


\section{Ampliando los significados de Sevicia: Los reclamos de protección corporal de los esclavos en Santiago de Cuba (1810-1870)}

El código de Las Siete Partidas. En Los códigos Españoles. (1848) Madrid: Imprenta La Publicidad.

Cano, B., \& de Zalba, F. (Eds.). (1875). El libro de los síndicos de ayuntamiento y de las juntas protectoras de libertos: Recopilación cronológica de las disposiciones legales a que deben sujetarse los actos de unos y otras. La Habana: Imprenta del Gobierno y Capitanía general por S.M.

Comisión Estadística. (1864). Noticias estadísticas de la isla de Cuba en 1862. La Habana: Imprenta del Gobierno.

Madden, R. R. (1849). The island of Cuba: Its resources, progress, and prospects, considered in relation especially to the influence of its prosperity on the interests of the British West India Colonies. London: C. Gilpin.

Manzano, J. F. (1996). Autobiografía de un esclavo. Detroit: Wayne State University Press.

Novísima Recopilación de las Leyes de España. (1805) Madrid. Recuperado de https://bvpb.mcu.es/es/consulta/registro.do?id=403945

O’Donnell, L. (1847). Cuadro estadístico de la siempre fiel isla de Cuba, correspondiente al año 1846. La Habana: Imprenta del Gobierno y de la Capitanía General.

Vives, D. (1829). Cuadro estadístico de la siempre fiel isla de Cuba correspondiente al año 1827. Madrid: Arazoza y Soler.

\section{Bibliografía}

Agüero, A. (2006). "Las categorías básicas de la cultura jurisdiccional." En Marta Lorente Sariñena (comp.); De justicia de jueces a justicia de leyes: hacia la España de 1870, Madrid: Consejo General del poder judicial - Centro de documentación judicial, 19-58.

Aguirre, C. (1995). Agentes de su propia libertad. Los esclavos de Lima y la desintegración de la esclavitud 1821-1854. Lima: Pontificia Universidad Católica del Perú.

Araujo, A. L. (2017). Reparations for Slavery and the Slave Trade: A Transnational and Comparative History. London: Bloomsbury Academic.

Barragan, Y. (2021). Freedom's Captives: Slavery and Gradual Emancipation on the Colombian Black Pacific. Cambridge: Cambridge University Press. 


\section{Adriana Chira}

Barragan, Y. (2021). "Commerce in Children: Slavery, Gradual Emancipation, and the Free Womb Trade in Colombia." The Americas 78(2): 229-257. Recuperado de DOI: https://doi.org/10.1017/tam.2020.136

Belmonte, José Luís (2011). Ser esclavo en Santiago de Cuba: Espacios de poder y negociación en un contexto de expansión y crisis, 1780-1803. Aranjuez: Doce Calles, 2011.

Bennett, H. (2005). Africans in Colonial Mexico: Absolutism, Christianity, and AfroCreole Consciousness, 1570-1640. Bloomington: Indiana University Press.

Bennett, H. (2018). African Kings and Black Slaves: Sovereignty and Dispossession in the Early Modern Atlantic. Philadelphia: University of Pennsylvania Press.

Benton, L. A., \& Ford, L. (2016). Rage for order: The British Empire and the origins of international law, 1800-1850. Cambridge: Harvard University Press.

Bermúdez Aznar, A. (1980). La abogacía de pobres en las Indias. Anuario de historia del derecho español, 1039-1054.

Berry, M. F. (2005). My Face Is Black Is True: Callie House and the Struggle for ExSlave Reparations. New York: Knopf.

Borah, W. (1983). Justice by Insurance: The General Indian Court of Colonial Mexico and the Legal Aides of the Half-Real. Berkeley: University of California Press.

Brewer-García, L. (2020). Beyond Babel: Translations of Blackness in Colonial Peru and New Granada. Cambridge: Cambridge University Press.

Brown, V. (2008). The Reaper's Garden: Death and Power in the World of Atlantic Slavery. Cambridge: Harvard University Press.

Browne, R. (2017). Surviving Slavery in the British Caribbean. Philadelphia: University of Pennsylvania Press.

Candioti, M. (2015). "Regulando el fin de la esclavitud. Diálogos, innovaciones y disputas jurídicas en las nuevas repúblicas sudamericanas 1810-1830", Jahrbuch für Geschichte Lateinamerikas. 52: 149-172. Recuperado de http://hdl.handle.net/11336/45005

Cañizares-Esguerra, J., Childs, M., \& Sidbury, J. (comps.). (2016). The Black Urban Atlantic in the Age of the Slave Trade. Philadelphia: University of Pennsylvania Press.

Carrasquillo, R. (2006). Our Landless Patria: Marginal Citizenship and Race in Caguas, Puerto Rico, 1880-1910. Lincoln: University of Nebraska Press. 


\section{Ampliando los significados de Sevicia: Los reclamos de protección corporal de los esclavos en Santiago de Cuba (1810-1870)}

Chalhoub, Sidney (2015). "The Politics of Ambiguity: Conditional Manumission, Labor Contracts, and Slave Emancipation in Brazil (1850-1888)," International Review of Social History 60 (2): 161-191. Recuperado de DOI: https://doi:10.1017/S0020859015000176

Chira, A. (2016). Uneasy Intimacies: Race, Family, and Property in Santiago de Cuba [PhD thesis]. University of Michigan.

Chira, A. (2018). "Affective Debts: Manumission by Grace and the Making of Gradual Emancipation Laws in Cuba, 1817-68." Law and History Review, 36(1), 1-33. Recuperado de https://doi.org/10.1017/S0738248017000529

Chira, A. (2021). "Manumission, Custom, and the Laws of Slavery and Freedom in Latin America." History Compass 19(2).

Recuperado https://doi.org/10.1111/hic3.12646

Cowling, C. (2013). Conceiving Freedom: Women of Color, Gender, and the Abolition of Slavery in Havana and Rio de Janeiro. Chapel Hill, University of North Carolina Press.

De la Fuente, A. (1988). Apuntes sobre la historiografía de la segunda mitad del siglo XVI cubano. Santiago, 71, 59-118.

De la Fuente, A. (2007). Slaves and the Creation of Legal Rights in Cuba: Coartación and Papel. Hispanic American Historical Review, 87(4), 659-692. Recuperado de DOI: https://doi.org/10.1215/00182168-2007-039

De la Fuente, A., \& Gross, A. J. (2020). Becoming Free, Becoming Black: Race, Freedom, and Law in Cuba, Virginia, and Louisiana. Cambridge: Cambridge University Press.

De la Torre, 0. (2018). The People of the River: Nature and Identity in Black Amazonia, 1835-1945. Chapel Hill. University of North Carolina Press.

Díaz, M. E. (2000). The Virgin, the King, and the Royal Slaves of El Cobre: Negotiating Freedom in Colonial Cuba, 1670-1780. Palo Alto: Stanford University Press.

Duharte Jiménez, R. (1988). El negro en la sociedad colonial. Santiago de Cuba: Editorial Oriente.

Eller, A. (2016). We Dream Together: Dominican Independence, Haiti, and the Fight for Caribbean Freedom. Durham: Duke University Press.

Fatah-Black, K. (comp.) (2020). Urban Slavery in the Age of Abolition. Dossier. International Review of Social History, 65(S28), 1-14. Recuperado de DOI: https://doi:10.1017/S0020859020000085 


\section{Adriana Chira}

Finch, A. K. (2015). Rethinking Slave Rebellion in Cuba: La Escalera and the Insurgencies of 1841-1844. Chapel Hill: University of North Carolina Press.

Finkenbine, R. E. (2007). "Belinda's Petition: Reparations for Slavery in Revolutionary Massachusetts." The William and Mary Quarterly, 64(1), 95-104. Recuperado de http://www.jstor.org/stable/4491599

Fradera, J. M. (2005). Colonias para después de un imperio. Barcelona: Ediciones Bellaterra.

Fraginals, M. M. (1978, 2014). El ingenio: Complejo económico social cubano del azúcar. La Habana: Editorial de Ciencias Sociales.

Franco, J. L. (1975). Las minas de Santiago del Prado y la rebelión de los cobreros, 1530-1800. La Habana: Editorial de Ciencias Sociales.

García Rodríguez, G. (2011). Voices of the Enslaved in Nineteenth-Century Cuba: A Documentary History. Chapel Hill: University of North Carolina Press.

Ghachem, M. W. (2011). "Prosecuting Torture: The Strategic Ethics of Slavery in PreRevolutionary Saint-Domingue (Haiti).” Law and History Review, 29(4), 985-1029. Recuperado de DOI: https://doi.org/10.1017/S0738248011000514

González Undurraga, C. (2012). "El abogado y el procurador de pobres: la representación de esclavos y esclavas a fines de la Colonia y principios de la República." Sudhistoria (5), julio-diciembre, 81-98. Recuperado de: URI: http://repositorio.uchile.cl/handle/2250/170529

Grinberg, K. (2001). "Freedom Suits and Civil Law in Brazil and the United States." Slavery \& Abolition 22(3): 66-82. Recuperado de https://doi:10.1080/714005211

Gudmundson, L., \& Wolfe, J. (2010). Blacks and Blackness in Central America: Between Race and Place. Chapel Hill: University of North Carolina Press.

Helg, A. (2019). Slave No More: Self-Liberation before Abolitionism in the Americas. (Trad. L. Vergnaud). Chapel Hill: University of North Carolina Press.

Hernández, M. D. (2014). La identidad de los esclavos negros como miserables en Nueva España: discursos y acciones (Siglos XVI-XVIII). En A. Martín Casares (comp.); Esclavitudes hispánicas (siglos XV al XXI: horizontes socioculturales. Granada, España: Universidad de Granada.

Herzog, T. (2004). Upholding Justice: Society, State, and the Penal System in Quito (1650-1750). Ann Arbor: University of Michigan Press.

Hespanha, A. H. (1992). Poder e instituções no antigo regime. Lisbon. 


\section{Ampliando los significados de Sevicia: Los reclamos de protección corporal de los esclavos en Santiago de Cuba (1810-1870)}

Hünefeldt, C. (1994). Paying the Price of Freedom: Family and Labor among Lima's Slaves, 1800-1854. Berkeley: University of California Press.

Hunt-Kennedy, S. (2020). Between Fitness and Death: Disability and Slavery in the Caribbean. Champaign: University of Illinois Press.

Jones, M. (2018). Birthright Citizens: A History of Race and Rights in Antebellum America. Cambridge: Cambridge University Press.

Leal, C. (2018). Landscapes of Freedom: Building a Postemancipation Society in the Rainforests of Western Colombia. Tucson: University of Arizona Press.

Lovejoy, H. B. (2018). Prieto: Yorùbá Kingship in Colonial Cuba during the Age of Revolutions. Chapel Hill: University of North Carolina Press.

Lucena Salmoral, M. (2000). Leyes para esclavos: El ordenamiento jurídico sobre la condición, tratamiento, defensa y represión de los esclavos en las colonias de la América española. Madrid: Fundación Histórica Tavera.

Lucena Salmoral, Manuel (1996). "La instrucción sobre educación, trato y ocupaciones de los esclavos de 1789. Una prueba de poder de los amos de esclavos frente a la debilidad de la Corona española." Estudios de historia social y económica de América 13:155-178.

Maia Mata, I. (2015) Conspiraçoes da raça de cor. Campinas: Editora da Unicamp.

Mattos, H. (2013) Das cores do silêncio. Campinas: Editora da Unicamp.

McKinley, M. (2016). Fractional Freedoms : Slavery, Intimacy, and Legal Mobilization in Colonial Lima, 1600-1700. Cambridge: Cambridge University Press.

Paquette, R. L. (1990). Sugar Is Made with Blood: The Conspiracy of la Escalera and the Conflict Between Empires Over Slavery in Cuba. Middletown: Wesleyan University Press.

Perera Díaz, A., \& Meriño Fuentes, M. de los Á. (2015). Estrategias de libertad: Un acercamiento a las acciones legales de los esclavos en Cuba (1762-1872). La Habana: Editorial de Ciencias Sociales. 2 tomos.

Portuondo Zúñiga, O. (1993). Santiago de Cuba, los colonos franceses y el fomento cafetalero (1798-1809). En J. Lamore (Ed.), Les français dans l'Orient cubain. Maison des Pays Ibériques. Bordeaux: Maison des Pays Ibériques.

Portuondo Zúñiga, O. (1996). Santiago de Cuba desde su fundación hasta la Guerra de los Diez Años. Santiago de Cuba: Editorial Oriente. 


\section{Adriana Chira}

Portuondo Zúñiga, O. (2010). Manuel Justo Rubalcava, el desconocido. Santiago de Cuba: Editorial Oriente.

Portuondo Zúñiga, O. (2012). El Departamento Oriental, 1510-1868: Dos temas de historia económica. Santiago de Cuba: Ediciones Santiago.

Premo, B. (2017). The Enlightenment on Trial: Ordinary Litigants and Colonialism in the Spanish Empire. Oxford: Oxford University Press.

Proctor, F. T., III. (2015). An "Imponderable Servitude": Slave versus Master Litigation for Cruelty (Maltratamiento or Sevicia) in Late Eighteenth-century Lima, Peru. Journal of Social History, 48(3), 662-684. Recuperado de https://doi.org/10.1093/jsh/shu120

Rebagliati, L. (2017).“'Un honorífico empleo': apuntes para el estudio de los abogados de pobres en el Río de la Plata (siglos XVIII-XIX)." Revista de la Facultade de Direito UFPR 62(3): 157-186. Recuperado de DOI: 10.5380/rfdufpr.v62i3.52965

Renault, A. (2012). D’une île rebelle a une île fidèle. Le Havre: Publications des universités de Rouens et du Havre.

Schneider, E. (2015). African Slavery and Spanish Empire: Imperial Imaginings and Bourbon Reform in Eighteenth-Century and Beyond. Journal of Early American History, 5, 3-29. Recuperado de DOI: https://doi.org/10.1163/1877070300501002.

Schneider, E. (2018). The Occupation of Havana: War, Trade, and Slavery in the Atlantic World. Chapel Hill: University of North Carolina Press.

Scott, R. La emancipación de los esclavos en Cuba: La transición al trabajo libre, 18601899. México, Fondo de cultura económica, 1989, 1983.

Scott, R. y Hébrard. J. (2014). Freedom Papers: An Atlantic Odyssey in the Age of Emancipation. Cambridge: Harvard University Press.

Tardieu, J-P. (2003). 'Morir o dominar': En torno al reglamento de esclavos de Cuba (1841-1866). Madrid: Iberoamericana.

Tau Anzoátegui, V. (2001). El poder de la costumbre: Estudios sobre el derecho consuetudinario en América hispana hasta la Emancipación. Buenos Aires, Instituto de Investigaciones de Historia del Derecho.

Turner, S. (2017). Contested Bodies: Pregnancy, Childrearing, and Slavery in Jamaica. Philadelphia: University of Pennsylvania Press. 
Ampliando los significados de Sevicia: Los reclamos de protección corporal de los esclavos en Santiago de Cuba (1810-1870)

Vallejo, V. (1992). "Power Hierarchies in Medieval Juridical Thought.” Ius commune 19: 1-29.

Hernández Reyes, C., Vergara Figueroa A. y Luz Cosme, C. (2018). Demando mi libertad: mujeres negras y sus estrategias de resistencia en la Nueva Granada, Venezuela y Cuba, 1700-1800. Cali: Universidad Icesi.

Recibido: 02/07/2021

Evaluado: 03/08/2021

Versión Final: 09/08/2021 